\title{
Finite element analysis of the tibial component alignment in frontal and sagittal plane in total knee arthroplasty
}

\author{
Roman Popescu' ${ }^{1}$, Stefan Cristea ${ }^{1,2}$, Adrian Marius Pascu' ${ }^{3}$, Valentin Oleksik', Emil George Haritinian ${ }^{1,4}$ \\ 1"Carol Davila" University of Medicine and Pharmacy, Bucharest, Romania \\ 2Department of Orthopaedics and Traumatology, "Sf. Pantelimon" Emergency Hospital, Bucharest, Romania \\ ${ }^{3}$ Department of Industrial Machinery and Equipments, Faculty of Engineering, "Lucian Blaga" University, Sibiu, Romania \\ ${ }^{4}$ Foisor Clinical Hospital of Orthopaedics and Traumatology and Osteoarticular TB, Bucharest, Romania
}

\begin{abstract}
Background. This study aims to analyse the tibial component using the finite element method by cutting the tibial in frontal and sagittal planes at an angle between $1.5^{\circ}$ (valgus and anterior tilt) and $-1.5^{\circ}$ (varus and posterior tilt).

Methods. This experimental study used the finite element method as an useful tool for simulating the positioning of the tibial component in order to create a personal pre-operative planning.

For the finite element method analysis, a geometrical model of a tibia from a cadaver was three - dimensionally scanned and the tibial component, polyethylene and cement, were three-dimensionally shaped in Computer-Aided Design program using material data such as Young modulus (gigapascal - GPa) and the Poisson coefficient. The analysis determined the equivalent von Mises stress, the maximum displacement of the components and the equivalent von Mises deformation. The results showed that equivalent tension and deformation have higher values in the tibia and the polyethylene, which deform faster than cement and the tibial component. In our study, we chose to simulate the tibial resection at a cutting angle $\pm 1.5^{\circ}$ from neutral positioning (which is represented in frontal plane by the perpendicular on the mechanical axis and in sagittal plane by the posterior slope of 7 degree) in frontal and sagittal plane in order to find the minimum threshold from which the tibial component malalignment may begin to determine unfavourable effects.

Results. Our results have shown detrimental effects begin to appear for the polyethene component at $-1.5^{\circ}$ in frontal plane, and the rest of the components at $1.5^{\circ}$ in sagittal plane.

Conclusion. This finding leads us to propose preoperative planning based on personal calculus of predefined angles, which may show the surgeon the optimal implantation position of the tibial component.
\end{abstract}

Keywords: finite element method, tibial component, total knee arthroplasty, varus alignment, sagittal alignment

\section{INTRODUCTION}

Total knee arthroplasty (TKA) is the most frequently used and effective treatment for advanced knee osteoarthritis. The implantation of the tibial component is a decisive factor for TKA's success, playing a key role in long-term outcomes (1-3).

Implant alignment in TKA is crucial for the functional results post-operative. The ideal alignment of the tibial component differs depending on each patient and anatomical singularities of the tibia. Literature data frequently describe effects of sagittal or coronal alignment, implying that component malpositioning has been associated with pain, accelerated polyethylene wear, joint instability, and eventually to TKA revision (4). Data reveal that, currently the revision risk of TKA at ten years is $5 \%$ (5). The 
positioning of the tibial component is still debatable, especially because the tibia's morphology is highly variable (6).

In the field of orthopaedics, the finite element analysis has become a very useful tool, especially in calculating stress, strain and deformation for the prosthetic components (7).

Tumulu et al. (8) studied material-model optimisation of knee prosthesis, while Suh et al. (9) created a computational study on the effect of malalignment of the tibial component on the biomechanics of TKA.

The purpose of our article is to conduct computational simulations using finite element analysis of the tibial component in coronal and sagittal planes. We will do this by cutting the tibia in frontal and sagittal planes at an angle between $1.5^{\circ}$ (represents valgus tilt and anterior tilt from neutral positioning) and $-1.5^{\circ}$ (represents varus tilt and posterior tilt from neutral positioning) in order to determine which tilt has negative consequences over the mechanical results in TKA. This experimental analysis could be implemented in preoperative planning to help the orthopaedic surgeon achieve better clinical results.

\section{MATERIALS AND METHODS}

This experimental study aims to use the finite element method as an useful tool for simulating the positioning of the tibial component in order to create a personal pre-operative planning.

For the finite element analysis, we used a three - dimensional scanner to scan the tibia's geometrical model of a cadaveric specimen. After scanning, the surfaces of the model were prepared for export in Computer-Aided Design (CAD) program through Computer-Aided Three-dimensional Interactive Application (CATIA). The analysis was made through Abaqus software after the geometrical inadvertences of the tibia were corrected. The tibial component, polyethylene and cement were not scanned, instead were three-dimensional shaped in CAD program according to another models. The geometry is the most important for $\mathrm{CAD}$ and is meshed in finite elements which are attached the material data, the geometrical data, and the type of element used (10-12). The material data used are the Young modulus (gigapascal-GPa) and Poisson ratio (Table 1).

TABLE 1. The material data used

\begin{tabular}{|l|c|c|}
\hline Component & Young modulus (GPa) & Poisson ratio \\
\hline Tibia & 6 & 0,3 \\
\hline Polyethylene & 10,9 & 0,46 \\
\hline $\begin{array}{l}\text { Tibial component } \\
\text { (titanium alloy) }\end{array}$ & 113,8 & 0,265 \\
\hline Cement & 14 & 0,1 \\
\hline
\end{tabular}

Legend: GPa-gigapascal
The tibia's geometry was sectioned to reduce the number of finite elements and the time for analysis. After importing and meshing the joint component's elements, the contacts were defined - for our analysis the "surface on surface" contact. The analysis is composed of three phases: pre-processing, solving and post-processing. The last phase shows graphically results of the analysis, which determines equivalent von Mises tension, maximum displacement of components, and equivalent von Mises deformation.

\section{RESULTS}

In both the frontal and sagittal plane, the proximal tibial cut was made at a $1.5^{\circ}$ (valgus and anterior) and at $-1.5^{\circ}$ (varus and posterior), and finite element analysis were made at these values.

For the tibia, we obtained the following results: the equivalent von Mises tension (the maximum stress comparable with the break limit of the bone), the equivalent von Misses deformation (comparable with the maximum deformation admitted by a certain material) and the nodal displacements on the three directions of the coordinate axes (table 2, figures 1-4).

TABLE 2. Results obtained for the tibia

\begin{tabular}{|l|c|c|c|}
\hline Analysis & $\begin{array}{c}\text { Equivalent } \\
\text { tension } \\
{[\mathrm{MPa}]}\end{array}$ & $\begin{array}{c}\text { Equivalent } \\
\text { deformation } \\
{[\mathrm{mm}]}\end{array}$ & $\begin{array}{c}\text { Nodal } \\
\text { displacement } \\
\text { [mm] }\end{array}$ \\
\hline $\begin{array}{l}\text { Proximal tibial cut at } \\
1.5^{\circ} \text { - frontal plane }\end{array}$ & 6.18 & 0.003 & 0.031 \\
\hline $\begin{array}{l}\text { Proximal tibial cut at } \\
-1.5^{\circ} \text { - frontal plane }\end{array}$ & 22.5 & 0.003 & 0.628 \\
\hline $\begin{array}{l}\text { Proximal tibial cut at } \\
1.5^{\circ} \text { - sagittal plane }\end{array}$ & 38.95 & 0.002 & 0.291 \\
\hline $\begin{array}{l}\text { Proximal tibial cut at } \\
-1.5^{\circ} \text {-sagittal plane }\end{array}$ & 21.81 & 0.003 & 0.343 \\
\hline
\end{tabular}

$\mathrm{MPa}$-megapascal, $\mathrm{mm}$ - millimetre
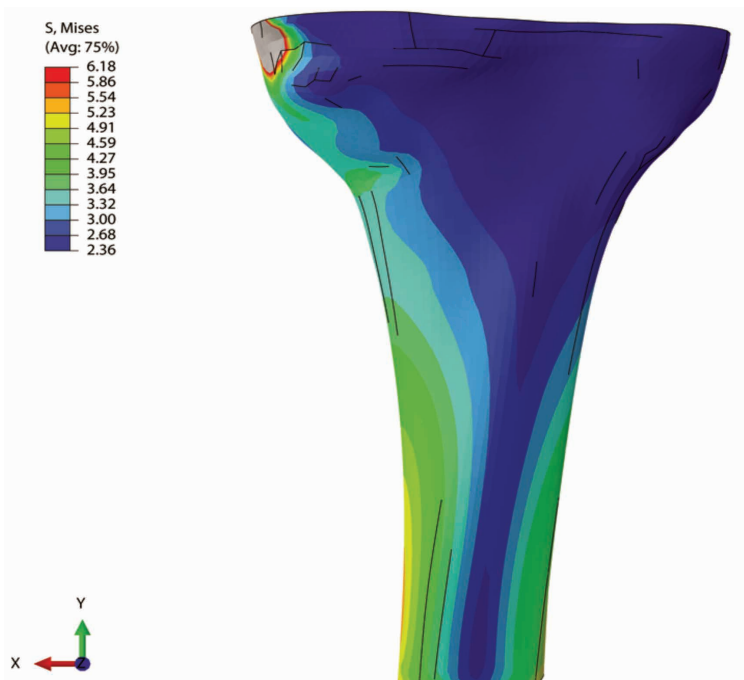

FIGURE 1. Variation of the equivalent von Mises stress for tibia in case of proximal resection at $1.5^{\circ}$ angle (valgus) in frontal plane 


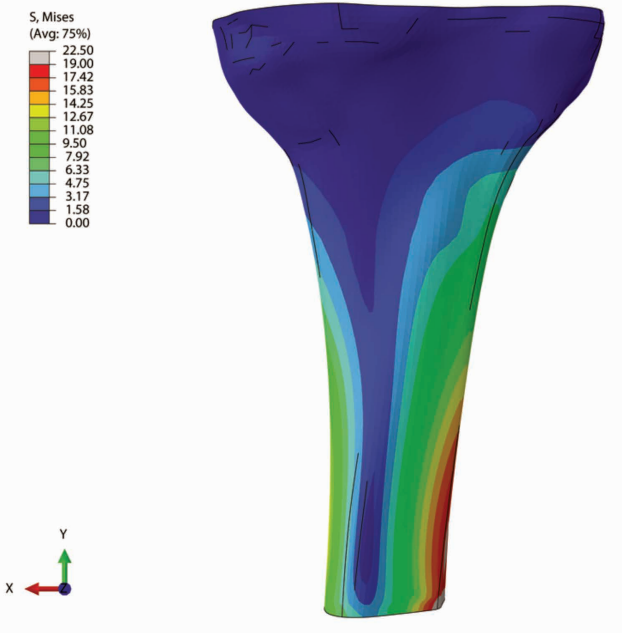

FIGURE 2. Variation of the equivalent von Mises stress for tibia in case of proximal resection at $-1.5^{\circ}$ angle (varus) in frontal plane

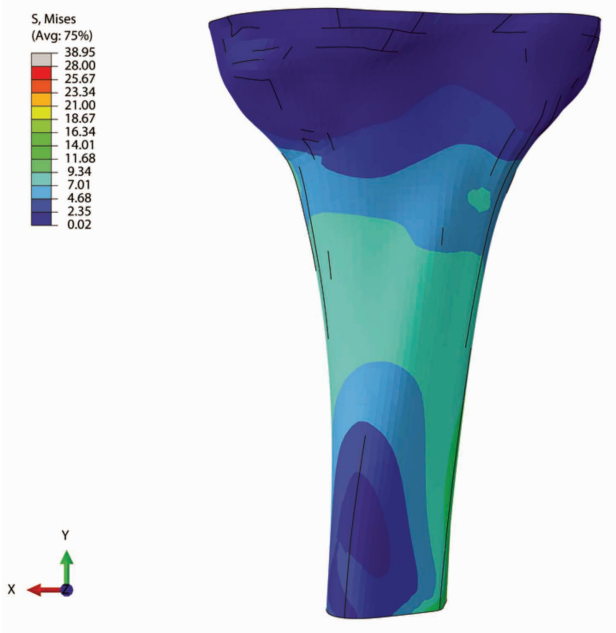

FIGURE 3. Variation of the equivalent von Mises stress for tibia in case of proximal resection at $1.5^{\circ}$ angle (anterior) in sagittal plane

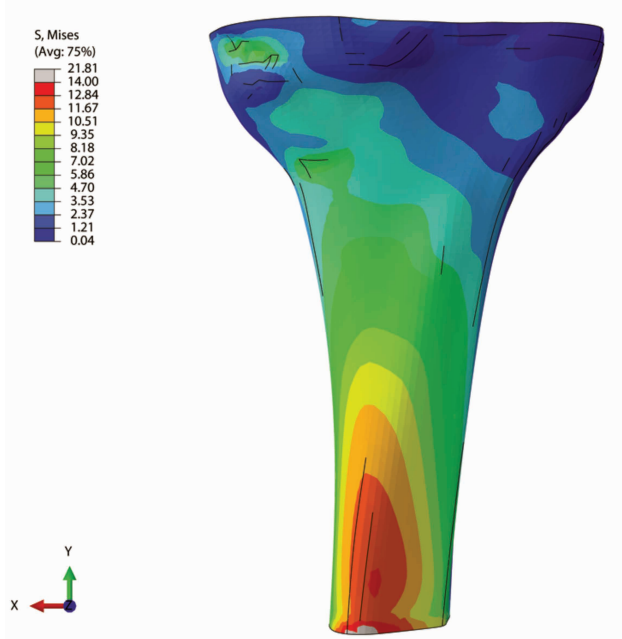

FIGURE 4. Variation of the equivalent von Mises stress for tibia in case of proximal resection at $-1.5^{\circ}$ angle (posterior) in sagittal plane
As for the rest (the tibial component, polyethylene and cement) we calculated only the equivalent von Mises stress and the main maximum deformation (tables 3-5).

TABLE 3. Results obtained for the tibial component

\begin{tabular}{|l|c|c|}
\hline Analysis & $\begin{array}{c}\text { Equivalent } \\
\text { tension [MPa] }\end{array}$ & $\begin{array}{c}\text { Equivalent } \\
\text { deformation }[\mathrm{mm}]\end{array}$ \\
\hline $\begin{array}{l}\text { Proximal tibial cut at } 1.5^{\circ} \\
\text { - frontal plane }\end{array}$ & 10 & 0.00015 \\
\hline $\begin{array}{l}\text { Proximal tibial cut at - } \\
1.5^{\circ} \text { - frontal plane }\end{array}$ & 11.8 & 0.00015 \\
\hline $\begin{array}{l}\text { Proximal tibial cut at } 1.5^{\circ} \\
\text { - sagittal plane }\end{array}$ & 49.3 & 0.00044 \\
\hline $\begin{array}{l}\text { Proximal tibial cut at } \\
-1.5^{\circ} \text { - sagittal plane }\end{array}$ & 20.5 & 0.00018 \\
\hline
\end{tabular}

$\mathrm{MPa}-$ megapascal

TABLE 4. Results obtained for the polyethylene

\begin{tabular}{|l|c|c|}
\hline Analysis & $\begin{array}{c}\text { Equivalent } \\
\text { tension [MPa] }\end{array}$ & $\begin{array}{c}\text { Equivalent } \\
\text { deformation [mm] }\end{array}$ \\
\hline $\begin{array}{l}\text { Proximal tibial cut at } \\
1.5^{\circ} \text { - frontal plane }\end{array}$ & 11.0310 & 0.00097 \\
\hline $\begin{array}{l}\text { Proximal tibial cut at } \\
-1.5^{\circ} \text { - frontal plane }\end{array}$ & 19.26 & 0.00225 \\
\hline $\begin{array}{l}\text { Proximal tibial cut at } \\
1.5^{\circ} \text { - sagittal plane }\end{array}$ & 5.12 & 0.00044 \\
\hline $\begin{array}{l}\text { Proximal tibial cut at } \\
-1.5^{\circ} \text { - sagittal plane }\end{array}$ & 6.388 & 0.00054 \\
\hline $\begin{array}{l}M P a-\text { megapascal }\end{array}$
\end{tabular}

TABLE 5. Results obtained for the cement

\begin{tabular}{|l|c|c|}
\hline Analysis & $\begin{array}{c}\text { Equivalent } \\
\text { tension [MPa] }\end{array}$ & $\begin{array}{c}\text { Equivalent } \\
\text { deformation [mm] }\end{array}$ \\
\hline $\begin{array}{l}\text { Proximal tibial cut at } \\
1.5^{\circ} \text {-frontal plane }\end{array}$ & 2.7 & 0.00020 \\
\hline $\begin{array}{l}\text { Proximal tibial cut at } \\
-1.5^{\circ} \text { - frontal plane }\end{array}$ & 3.1 & 0.00020 \\
\hline $\begin{array}{l}\text { Proximal tibial cut at } \\
1.5^{\circ} \text { - sagittal plane }\end{array}$ & 8.2 & 0.00032 \\
\hline $\begin{array}{l}\text { Proximal tibial cut at } \\
-1.5^{\circ} \text { - sagittal plane }\end{array}$ & 3.3 & 0.00020 \\
$M P a-$ megapascal & & \\
\hline
\end{tabular}

In our study, referring to the tibia, the maximum equivalent tension is obtained in case of proximal tibial resection at $1.5^{\circ}$ angle in sagittal plane (anterior tilt), which is also obtained for the tibial component and cement. As to the polyethylene, the maximum equivalent tension is obtained in case of proximal tibial cut at $-1.5^{\circ}$ in frontal plane (varus tilt). Taking into consideration that the polyethylene is the component that wears out the most, our analysis points that the maximum deformation for the polyethylene occurs in the proximal tibial cut at $-1.5^{\circ}$ in frontal plane, suggesting that accelerated wear happens with varus tilt.

While in the literature data the tibial component deviation in sagittal plane of $\pm 1.5^{\circ}$ it is not consid- 
ered a problem, the finite element method shows that even such small deviations influence the bone underlying the prosthetic, respectively the polyethylene component, even though it has no immediate effect on the clinical outcomes.

\section{DISCUSSIONS}

Total knee arthroplasty (TKA) is a surgical procedure that improves knee function, alleviates knee pain, and improves patient's life. The success of TKA depends on factors like soft tissue balancing, post-operative alignment and prosthetic component implantation. Nowadays, approximately $20 \%$ patients with TKA are dissatisfied with the clinical results and about $9 \%$ have pain because of the tibial component malalignment (13).

Mangiapani et al. found that TKA alignment is a relative concept - meaning it defines both the component alignment and the limb alignment (14).

Coronal tibial component malalignment is associated with higher polyethylene stress and patellofemoral complications, especially clinically - the varus tibial component alignment is highly dissatisfying, with higher stress on the polyethylene than in valgus tibial component alignment $(15,16)$.

Sagittal alignment in TKA is kinematically important, mainly because the most common moves (flexion, extension) occur in this alignment (17).

According to the results we obtained through finite element analysis, unfavourable effects begin to appear in case of proximal tibial cut at $1.5^{\circ}$, which means positioning anterior the tibial component in the sagittal plane. The results from table 2-5 show that equivalent tension and deformation have higher values in the tibia and the polyethylene, which deform faster than cement and the tibial component.

Gromov et al. studied the tibial angle at a value between $0^{\circ}$ and $7^{\circ}$ and found that a value less than $0^{\circ}$ and more than $7^{\circ}$ has a failure rate of $4,5 \%$ due to prosthetic knee instability (18).

Some studies support the hypothesis that frontal alignment in varus is associated with higher failure rate (tibial component loosening, faster wear of the polyethylene) and leads to a faster degradation of the medial knee compartment $(19,20)$. It also generates unequal distribution of loads at the level of the two compartments and overall knee instability $(19,20)$.

Jeffcote et al. concluded that in some models of tibial prostheses, the valgus alignment determines a lower contact pressure at the level of the spongious bone underlying the prosthesis, while Green et al. claimed that varus tibial component positioning increases the risk of TKA failure $(15,19)$. Moreover, Green et al. imply that beneath a varus tibial com- ponent, the tibial bone subsides (especially in the medial compartment) due to the compression overload with radiolucent tibial lines as corresponding radiological result (19).

Perillo-Marcone et al. found that the stress that occurs over the prosthetic underlying bone is taken by the metallic, polyethene and cement components, but even in these conditions the underlying tibia is subjected to increased loads on repeated moves, especially due to sagittal malalignment (20).

Berend et al. (21) suggest that a value $>3^{\circ}$ in varus for the tibial component increases the risk of TKA failure, but the results of our finite element analysis show that the degradation of the polyethylene may start from even lower values $\left(-1.5^{\circ}\right)$. This fact may have major clinical implications, thus improving the evolutionary course of TKA, especially in the long-term.

In line with our results, Matsuda et al. also found that a correlation exists between the varus tibial component alignment and polyethylene wear because the varus alignment changes the distribution of tibial loading (22).

Katimani found that in sagittal plane, the proximal tibial cut should never be made with anterior slope, because it could affect flexion and could determine knee instability (23).

In their article, Srivasta et al. (16) conclude that varus tibial component alignment of a mean $1.3^{\circ}$ can determine fast polyethylene wear, while Suh et al. (9) consider that varus alignment increases the polyethylene wear in the medial compartment leading to joint instability and eventually to TKA failure.

Our experimental study has limitations. Firstly, the simulation was made on a tibia in static conditions (tibia from a cadaveric specimen). Because of this, we were not able to do a simulation during a gait cycle using the same values of simulation to observe the wear during a greater pressure loading on the polyethylene insert.

Second, the tibia was a normal bone (without deformities) and without pathological changes such as osteoporosis. Also, the bone properties and geometry were from a single cadaver specimen, so we did not account for individual variability.

TKA results have improved over time through technological advances, improved and more durable prosthetic components, increased surgical experience, and better operative technique. However, $20 \%$ of patients are not satisfied with TKA results, mainly because of the tibial component alignment.

\section{CONCLUSIONS}

In our study, we chose to simulate the tibial resection on $\pm 1.5^{\circ}$ angle in the frontal and sagittal planes to find the minimum threshold from which 
the tibial component malalignment may begin to determine unfavourable effects (which begin for the polyethylene component at $-1.5^{\circ}$ in the frontal plane - varus alignment, and the rest of the components at $1.5^{\circ}$ in sagittal plane). This finding led to the

\section{REFERENCES}

1. Stan G, Orban H, Gruionu L, Gheorghe P. Coronal malposition effects in total knee arthroplasty: a finite element analysis. Eur J Orthop Surg Traumatol. 2013 Aug;23(6):685-90.

2. Parisi TJ, Jennings JM, Dennis DA. Coronal Alignment in TKA: Traditional Principles Versus New Concepts. Reconstructive Review 2018; 8(2):19-28.

3. Ma DS, Wang ZW, Wen L, Ren SX, Lin Y, Zhang B. Improving Tibial Component Coronal Alignment During Total Knee Arthroplasty with the Use of a Double-Check Technique. Orthop Surg. 2019 Dec; 11(6):1013-1019.

4. Bédard M, Vince KG, Redfern J, Collen SR. Internal rotation of the tibial component is frequent in stiff total knee arthroplasty. Clin Orthop Relat Res. 2011 Aug;469(8):2346-55.

5. Khan M, Osman K, Green G, Haddad FS. The epidemiology of failure in total knee arthroplasty: avoiding your next revision. Bone Joint J. 2016 Jan;98-B(1 Suppl A):105-12.

6. Dai Y, Scuderi GR, Bischoff JE, Bertin K, Tarabichi S, Rajgopal A. Anatomic tibial component design can increase tibial coverage and rotational alignment accuracy: a comparison of six contemporary designs. Knee Surg Sports Traumatol Arthrosc. 2014 Dec; 22(12):2911-23.

7. Arab AZE, Merdji A, Benaissa A, Roy S, Bachir Bouiadjra BA, Layadi K, Ouddane A, Mukdadi OM. Finite-Element analysis of a lateral femoro-tibial impact on the total knee arthroplasty. Comput Methods Programs Biomed. 2020 Aug;192:105446.

8. Tumulu S, Sarkar D. Computer-aided design, finite element analysis and material-model optimisation of knee prosthesis. J Aust Ceram Soc. 2018;54:429-438.

9. Suh DS, Kang KT, Son J, Kwon OR, Baek C, Koh YG. Computational study on the effect of malalignment of the tibial component on the biomechanics of total knee arthroplasty: A Finite Element Analysis. Bone Joint Res. 2017 Nov;6(11):623-630.

10. MacDonald BJ. Practical stress analysis with finite elements (Modelling and meshing), 2nd ed. Glasnevin Publishing, 2007:179-210.

11. Danczyk J, Suresh K. Finite Element Analysis Over Tangled Meshes. Proceedings of the ASME 2012 International Design Engineering Technical Conferences and Computers and Information in Engineering Conference. Volume 2: 32nd Computers and Information in Engineering Conference, Parts A and B. Chicago, 2012:89-95. proposal of preoperative planning based on personal calculus of predefined angles which may show the surgeon the optimal implantation position of the tibial component.
12. Fries TP, Belytschko T. The extended/generalized finite element method: An overview of the method and its applications. Int I Numer Meth Engng. 2010;84(3):253-304.

13. Suchowersky AM, Dickison D, Ashton LA. Current variability in the assessment of component position for the unhappy knee replacement. ANZ J Surg. 2020 Jul;90(7-8):1246-1252.

14. Mangiapani DS, Schaeffer JF, Myers AR, Hofmann AA. Less valgus alignment in total knee arthroplasty for the varus knee. Semin Arthroplasty. 2018;29(1):36-41.

15. Jeffcote B, Shakespeare D. Varus/valgus alignment of the tibial component in total knee arthroplasty. Knee. 2003 Sep;10(3):243-7.

16. Srivastava A, Lee GY, Steklov N, Colwell CW Jr, Ezzet KA, D'Lima DD. Effect of tibial component varus on wear in total knee arthroplasty. Knee. 2012 Oct;19(5):560-3.

17. Yoo JH, Chang CB, Shin KS, Seong SC, Kim TK. Anatomical references to assess the posterior tibial slope in total knee arthroplasty: a comparison of 5 anatomical axes. J Arthroplasty. 2008 Jun; 23(4):586-92.

18. Gromov K, Korchi M, Thomsen MG, Husted H, Troelsen A. What is the optimal alignment of the tibial and femoral components in knee arthroplasty? Acta Orthop. 2014 Sep;85(5):480-7.

19. Green GV, Berend KR, Berend ME, Glisson RR, Vail TP. The effects of varus tibial alignment on proximal tibial surface strain in total knee arthroplasty: The posteromedial hot spot. J Arthroplasty. 2002 Dec;17(8):1033-9.

20. Perillo-Marcone A, Barrett DS, Taylor M. The importance of tibial alignment: finite element analysis of tibial malalignment. J Arthroplasty. 2000 Dec;15(8):1020-7.

21. Berend ME, Ritter MA, Meding JB, Faris PM, Keating EM, Redelman R, Faris GW, Davis KE. Tibial component failure mechanisms in total knee arthroplasty. Clin Orthop Relat Res. 2004 Nov;(428):26-34.

22. Matsuda S, Whiteside LA, White SE. The effect of varus tilt on contact stresses in total knee arthroplasty: a biomechanical study. Orthopedics. 1999 Mar;22(3):303-7.

23. Raviprasad K. Component Alignment in Total knee Replacement. Ortho \& Rheum Open Access J. 2018;11(3):555815. 